\title{
Tabularia
}

\section{Le testament de Louis de Bourbon-Vendôme, évêque d'Avranches (1510)}

The testament of Louis de Bourbon-Vendôme, Bishop of Avranches (1510)

\section{Vincent Tabbagh}

\section{(2) OpenEdition \\ Journals}

Édition électronique

URL : http://journals.openedition.org/tabularia/2555

DOI : 10.4000/tabularia.2555

ISSN : $1630-7364$

Éditeur :

CRAHAM - Centre Michel de Boüard, Presses universitaires de Caen

\section{Référence électronique}

Vincent Tabbagh, «Le testament de Louis de Bourbon-Vendôme, évêque d'Avranches (1510) », Tabularia [En ligne], Sources en ligne, mis en ligne le 11 avril 2014, consulté le 01 mai 2019. URL http://journals.openedition.org/tabularia/2555 ; DOI : 10.4000/tabularia.2555 


\title{
Le testament de Louis de Bourbon-Vendôme, évêque d'Avranches (1510)
}

\author{
The testament of Louis de Bourbon-Vendôme, \\ Bishop of Avranches (1510)
}

\author{
Vincent TABBAGH \\ UMR ArTeHiS, université de Bourgogne \\ vincent.tabbagh@sfr.fr
}

Résumé:

Fils légitimé d'un prince, évêque réformateur, mécène et humanisant, Louis de BourbonVendôme laisse en 1510 un testament où il se montre peu soucieux de vénération des saints, de fondations perpétuelles et de legs charitables, assuré qu'il est de son propre salut par la grâce de sa consécration au point de constituer en autant de reliques les trois parties de son corps dont il a demandé le démembrement, tête, cœur et ossements.

Mots-clés: testament, évêque, inhumation, cadavre, reliques, sainteté, mécénat

\begin{abstract}
:
Legitimate son of a prince, reforming bishop, philanthropist and humanist, Louis de Bourbon-Vendôme left in 1510 a testament in which he shows little interest in veneration of saints, perpetual foundations and charitable bequests. However to assure his own salvation by the grace of his consecration, to constitute as many relics from three parts of his body, head, heart and bones, he asked to be dismembered.
\end{abstract}

Keywords: testament, bishop, burial, body, relics, holiness, philanthropy

Les testaments attirent depuis longtemps l'attention. Source relativement abondante à partir du XIII ${ }^{e}$ siècle et surtout du suivant, l'ampleur de ce qu'ils livrent à propos d'un individu particulier les rend même exceptionnels: la fortune, les affaires, la carrière y font entendre de précieux échos, mais aussi la famille, l'entourage de serviteurs et d'amis, tout comme les attitudes spirituelles, les gestes d'inhumation, les croyances quant à l'au-delà. Malgré la contrainte d'une composition normalisée et des formules répétitives, des choix réfléchis et personnels s'y expriment. Ils concernent des milieux variés, depuis les princes et les prélats jusqu'à des bourgeois ou des paysans aisés. Dans certains diocèses au moins l'Église en impose la pratique, plaçant la dépouille et les biens de l'intestat dans une situation juridique plus ou moins fâcheuse. Leur

Tabularia «Documents», $\mathrm{n}^{\circ}$ 14, 2014, p. 1-27, 11 avril 2014 http://www.unicaen.fr/mrsh/craham/revue/tabularia/print.php?dossier=sources\&file=12tabbagh.xml 
nombre a permis parfois, pour des espaces précis mais une chronologie longue, souvent deux siècles, leur traitement sériel, jetant une lumière vive sur de fortes différences régionales et sociales: les démarches individuelles s'insèrent dans la culture religieuse d'un milieu, déclinaison particulière de celle du christianisme médiéval dans son ensemble ${ }^{1}$. L'ampleur des recherches récentes qui les prennent pour source première permet aujourd'hui de saisir les originalités et spécificités de certains d'entre eux comme celui de Louis de Bourbon-Vendôme, et d'avancer ainsi dans la connaissance des conceptions qu'un prélat se fait de son cadavre, de son salut et de sa propre dignité, peu avant les grandes remises en cause de la Réforme.

Les pertes documentaires ont rendu peu nombreux les testaments épiscopaux de la France flamboyante, d'où l'attention méritée par celui du titulaire d'Avranches. Dicté à deux notaires apostoliques, le scribe du chapitre de la collégiale Saint-Martin de Tours, Guillaume du Moulin, prêtre, curé de Clamart au diocèse de Paris, et Louis François, clerc du diocèse de Chartres, licencié en décret, qui l'ont présenté comme un instrument public, authentifié de leur paraphe, il est arrivé dans les fonds de l'archevêché de Rouen parce que le métropolitain détenait la juridiction sur l'exécution testamentaire de ses suffragants ${ }^{2}$, mais une copie de la traduction française en fut recueillie sans doute peu de temps après dans une collection de testaments princiers ${ }^{3}$. L'évêque n'y livre que de rares renseignements sur sa fortune, sa famille ou son entourage car, contrairement à beaucoup d'autres, il ne prévoit pas de legs; il y restreint l'expression d'une dévotion que certains auraient déployée dans de denses formules d'invocations, de recommandations et de justifications, mais il met son soin à organiser ses funérailles et ses sépultures comme, dans une moindre mesure cependant, les prières perpétuelles destinées à sa mémoire. Les dispositions concernant le devenir de son corps atteignent une grande précision. Dans un codicille passé le même jour, devant les mêmes notaires, et dont ne subsiste plus que la copie de la traduction française, il se préoccupe d'un certain nombre de dettes, dont il demande l'apurement, et de l'audition des comptes de son temporel après son décès: il a voulu conserver au testament lui-même une dimension purement spirituelle 4 .

1. Parmi les études les plus significatives, qui ont marqué l'historiographie, on peut retenir, pour celles qui reposent sur un corpus régional: Chiffoleau, 2011; Desportes, 2003; Folz, 1955; Fournié, 1997; Hayez, 1977, I, p. 129-159; Lorcin, 1981; Marandet, 1998; Pasche, 1989; StoufF, 1998, p. 199-222.

Les travaux portant sur une catégorie de testateurs sont plus rares: pour les princes, GAUDEFerragu, 2005; pour les évêques: Jourd'HeUil, 2010; pour les nobles: PÉGEOT, 1983, p. 303-318; pour les officiers royaux: Courtemanche, 1997.

2. Parchemin de $52 \mathrm{~cm}$ de hauteur sur $68 \mathrm{~cm}$ de largeur. Rouen, Arch. dép. Seine-Maritime, G 8680. Ce texte avait suscité l'attention de Charles de Beaurepaire, archiviste de ce département, qui l'a publié en 1895, avec une courte introduction: BEAUREPAIRE, 1895, p. 344-355.

3. Paris, Arch. nat., K $538 \mathrm{n}^{\circ} 8$. Je dois l'indication de cette source à Jean-Vincent Jourd'heuil, qu'il s'en trouve ici vivement remercié. L'écriture paraît du début du XVI ${ }^{\mathrm{e}}$ siècle.

4. Paris, Arch. nat., $\mathrm{K} 538 \mathrm{n}^{\circ} 8$, à la suite du testament. 


\section{Origine et carrière}

Louis était le fils illégitime de Jean de Bourbon, comte de Vendôme, et de Guyonne ou Guidone Peignée de Vieuxville ou La Vieuxville ${ }^{5}$. Son père, descendant de saint Louis, appartenait à une branche cadette de la maison ducale de Bourbon, celle des comtes de la Marche, détachée de l'aînée au $\mathrm{XIV}^{e}$ siècle en la personne de Jacques, fils cadet du duc Louis $\mathrm{I}^{\mathrm{er}}$ et frère du duc Pierre I ${ }^{\text {er }}$. À la mort du dernier comte de la Marche, Jacques, en 1438 , cet important domaine passa par le mariage de son héritière à un fils cadet du comte d'Armagnac; Louis de Bourbon, frère de Jacques et grand-père de l'évêque d'Avranches, n'eut comme terre éminente que le comté de Vendôme, qui lui venait de sa mère. Né sans doute dans les années 1450, avant 1454 même pour avoir au moins trente ans lors de son élévation épiscopale en 1484, donc sans doute avant le mariage de son père avec son épouse légitime Isabelle de Beauvau intervenu en novembre $1454^{6}$, il reçut la tonsure des mains de l'évêque de Chartres, le 2 octobre 1466, ce qui laisse supposer qu'il fut élevé à Vendôme. Les pratiques bien établies entre le roi et les familles princières lui permirent d'être légitimé en novembre $1469^{7}$. Il fréquenta ensuite une université, sans doute celle d'Orléans, où il acquit la licence en droit civil, grade qu'il détenait en mars 1480 lorsqu'il obtint l'administration de la léproserie de Vendôme. En 1483 et 1484, protonotaire apostolique, il siégeait comme conseiller au Parlement de Paris et parallèlement possédait d'autres bénéfices ecclésiastiques sans cure d'âmes, ce qui l'autorisait à rester simple clerc: la chantrerie de la collégiale Saint-Georges de Vendôme, seconde dignité de ce chapitre, par faveur de son père sans doute, et le prieuré Saint-Thomas d'Épernon, dépendant de l'abbaye bénédictine de Marmoutier près de Tours, aux revenus certainement plus substantiels, une commende qui ne le contraignit pas à prononcer des voux. Épernon était l'une des nombreuses seigneuries du comte de Vendôme ${ }^{8}$. Peutêtre fut-il aussi chanoine d'Avranches, cité dont il devint l'évêque en 1484, à un moment où aucune législation claire et cohérente ne s'imposait en matière d'accès aux sièges épiscopaux, le Concordat de 1472 ayant été dénoncé en 1478 et les États généraux de janvier à avril 1484 ayant réclamé, mais sans l'obtenir, le rétablissement de la Pragmatique Sanction de 1438, donc le retour officiel

5. Louis de Bourbon-Vendôme a fait l'objet d'un certain nombre de notices dans des travaux plus ou moins anciens. Gallia christiana, VIII, col. 1377, XI, col. 495 et 550. ANSELME, 1726, I, p. 524-525. Nicole, 1898, p. 82-85. LeCAnu, 1877-1878, I, p. 410. PigeOn, 1888, p. 684. Dictionnaire d'Histoire et de Géographie ecclésiastiques, X, col. 132-133. De ces notices sont tirés tous les renseignements de cette étude à ne pas être explicitement référencés.

6. Son père eut aussi un autre fils illégitime, Jacques, qui recevra la baronnie de Ligny, d'une femme nommée Philippe de Gournay. Jacques paraît né bien après l'évêque, son propre fils aîné ayant vu le jour vers 1515: Anselme, 1726, I, p. 578-579. Leur père, contrairement aux autres familles princières, donne à ses bâtards des prénoms en usage dans la lignée légitime.

7. C'est la date que donne une note qui paraît cependant assez tardive: BnF, Pièces originales 456, $\mathrm{n}^{\circ}$ 260. La Gallia christiana indique 1499.

8. Dép. Eure-et-Loir, cant. Maintenon. 
des élections ${ }^{9}$. Comme son prédécesseur Jean Boucart décéda à Saint-Lô le 28 novembre 1484 et que les bulles d'Innocent VIII qui lui donnèrent ce siège datent du 17 décembre suivant, il s'est écoulé un temps suffisant pour qu'une élection capitulaire ait pu se produire; en tout cas personne ne lui contesta cette dignité et quand d'autres faisaient référence au siège apostolique dans leur titulature, il se présentait comme évêque "par l'intercession divine ${ }^{10}$. Qu'ils l'aient élu ou simplement accepté, les chanoines voyaient bien tous les avantages que l'Église d'Avranches pourrait retirer d'un prélat de haute naissance. $\mathrm{Au} \mathrm{XV}^{\mathrm{e}}$ siècle, plusieurs bâtards de prince accédèrent à un siège épiscopal, d'importance proportionnelle au rang de leur père: fils d'un membre d'une branche cadette, Louis dut se contenter du plus petit et du moins riche des diocèses normands, quand son lointain cousin Renaud de Bourbon, bâtard du duc Charles I ${ }^{\text {er }}$, obtenait l'évêché de Laon puis l'archevêché de Narbonne.

À l'exemple de nombreux évêques de son temps, mais sans que cela soit une pratique générale, il reçut des abbayes ou prieurés destinés à compléter ses revenus, l'absence de règles de droit précises pour ces nominations entraînant leur multiplication pour un même bénéfice, donc de fréquentes concurrences, d'où procès puis accords amiables avec répartition des revenus par des pensions versées par le titulaire à ses anciens rivaux. Louis de Bourbon renonça ainsi en juillet 1489 à ses droits sur l'abbaye de chanoines augustins Saint-Jean à Sens, au profit de l'archevêque de cette cité, Tristan de Salazarrl. De 1489 à 1493, une compétition l'opposa à frère Louis de Cravant pour l'abbaye de la Trinité de Vendôme, avant qu'il abandonnât là aussi ses droits bien que le roi l'eût appuyééc. Il en retira cependant une pension sur les revenus de la mense abbatiale. En 1499, il obtint de Louis XII, contre Claude de Dinteville, peut-être élu par les moines, en tout cas reconnu par le chapitre général de Cîteaux cette année-là, l'abbaye cistercienne de Savigny, dans son diocèse ${ }^{13}$; il la conserva jusqu'à sa mort; cette communauté chef d'ordre était à la tête d'un réseau dense qui donnait à son abbé une influence considérable: dans le seul diocèse d'Avranches, elle patronnait douze paroisses. L'abbaye de Saint-Georges-du-Bois, dans le Vendômois, un établissement modeste autrefois bénédictin, peuplé à son époque de chanoines réguliers de saint Augustin, lui échut en $1508^{14}$. Il possédait également la dignité de cellérier dans l'abbaye bénédictine de L'Ile-Barbe, proche de Lyon ${ }^{15}$.

La cour de France le tenait incontestablement en estime; s'il ne siégea plus au Parlement une fois revêtu de l'épiscopat ${ }^{16}$, il fut présent à l'Échiquier de

9. JULEROT, 2006, p. 59-61.

10. Par exemple dans une quittance de 1499: Paris, BnF, Pièces originales 456, fol. $163, \mathrm{n}^{\circ} 184$.

11. Auxerre, Arch. dép. Yonne, G 207 fol. $68 \mathrm{v}$.

12. PÉlICIER, 1898-1905, III, p. 66 et 202.

13. Canivez, 1938, p. 220.

14. Dép. Loir-et-Cher, cant. Montoire, c. Saint-Martin-du-Bois. Affiliée à Marmoutier au XII ${ }^{e}$ siècle, cette abbaye est dite explicitement appartenir à l'ordre de saint Augustin par le Pouillé du diocèse du Mans rédigé en 1508. Longnon, 1903, p. 99 A.

15. Dép. Rhône, cant. Limonest, c. Saint-Rambert-L'Ile-Barbe.

16. Paris, BnF, ms français 4391, fol. 25. 
Normandie en 1497 et 1500 et aurait fait partie de plusieurs ambassades ${ }^{17}$. Il touchait du roi une pension de 400 livres par an, comme le montre une quittance datée de 1499. Le 31 mars 1500/1501, Louis XII le nomma commissaire pour le gouvernement du temporel de l'abbaye de Saint-Wandrille au diocèse de Rouen; il portait alors le titre de conseiller du roi $^{18}$. Avant septembre 1503, il lui prêta mille livres pour ses guerres, autant que l'archevêque de Bourges ${ }^{19}$. À Rouen, le 29 juin 1510, il présida la grandiose cérémonie des obsèques du cardinal Georges d'Amboise: il n'était alors pourtant ni le premier ni le doyen de ses suffragants ${ }^{20}$. Ses liens avec la cour le conduisaient souvent sur les bords de Loire ${ }^{21}$ et c'est à Tours qu'il testa le 17 octobre 1510 et mourut quatre jours plus tard.

\section{L'activité pastorale et l'entourage de l'évêque}

On connaît assez mal l'activité de Louis de Bourbon durant les vingt-quatre années de son épiscopat. Quelques traces montrent cependant qu'il pratiqua régulièrement, dès 1485, des visites pastorales, examinant la réserve eucharistique, les huiles saintes, les fonts baptismaux, exigeant la réparation des églises, la clôture des cimetières, la rédaction de livres liturgiques, donnant la confirmation ${ }^{22}$. Pendant les années 1494 à 1496 au moins, il accomplit des tournées afin de tonsurer les enfants et les adolescents, réconciliant en même temps les églises polluées. Il sut dépasser les cadres institutionnels lorsqu'il réunit autour de lui ses principaux officiers et le chapitre cathédral dans une salle de son manoir, le 15 avril $1496^{23}$. Sa volonté de visiter les abbayes dépendantes de Savigny, jusqu'au diocèse de Thérouanne pour celle de Longvillers en 1509 par exemple, provoqua la colère du chapitre général de Cîteaux, d'autant plus qu'elle semble avoir fait écho à la recherche par ces maisons d'une plus grande autonomie à l'égard de l'ordre ${ }^{24}$. Apparaît dans le codicille de son testament comme maitre des novices

17. Cette affirmation d'une place dans des ambassades figure d'abord dans un éloge que fit de lui son successeur sur le siège d'Avranches au milieu du XVI ${ }^{e}$ siècle, Robert Céneau: Gallia christiana, XI, col. 495 .

18. Paris, BnF, Pièces originales 456, p. $164, \mathrm{n}^{\circ} 189$.

19. Paris, BnF, Pièces originales 456, p. $167, \mathrm{n}^{\circ} 196$.

20. Funérailles de Georges d'Amboise..., 1864.

21. L'information selon laquelle, à Tours, le 5 août 1484, il assista l'archevêque comme prélat consécrateur du nouveau titulaire de Bourges, Pierre Cadoët, ne peut cependant être retenue: d'après les dates, l'évêque d'Avranches est alors Jean Boucart. Julerot, 2006, p. 319.

22. Lechat, 1957, 12 p. Le procès-verbal de la visite de Saint-Martin de Beuvron a été publié par le chanoine MÉNARD, 1896, p. 105-106.

23. Beaurepaire, [sd] p. 3-9 pour les tournées d'ordres, p. 47 pour la réunion avec le chapitre, p. 51 pour la réconciliation par l'évêque de l'abbatiale du Mont Saint-Michel.

24. Le chapitre général de 1503 proteste contre le fait qu'il ait donné commission à des religieux de Savigny de visiter Veterivilla (La Vieuville dans le diocèse ancien de Dol, dép. Ille-et-Vilaine, cant. Dol); en 1507 il décide d'agir juridice et viriliter contre l'évêque qui veut visiter contre les privilèges de l'ordre et en 1509 il désigne deux ou trois abbés pour sévir contre celui de Longovillari qui a refusé l'entrée à l'abbé de Cîteaux en personne alors qu'il avait accepté celle de Louis de Bourbon. CANIVEZ, 1938, p. 288-289, p. 350, p. 373. Longvillers se trouve dans l'ancien diocèse de Thérouanne, dép. Pas-de-Calais, cant. Étaples. 
de l'abbaye de Saint-Georges-du-Bois un professeur de théologie qui figure dans son entourage depuis de nombreuses années, Jean Le Masson, dont il fit aussi son vicaire général pour l'abbaye de Savigny et qui visitait en son nom certaines paroisses importantes, comme celle de Mortain: le choix de cet homme de confiance montre son souci d'une bonne formation du clergée 25 . Ce codicille trahit par ailleurs l'ampleur de ses scrupules en matière de bonne gestion de ses revenus et des biens temporels de ses bénéfices. Il fit éditer un missel diocésain, par souci de rigueur liturgique sans doute. Tous ces éléments suggèrent un prélat zélé, en tout cas exact dans l'exercice de son ministère et soucieux de rassembler toutes les forces du diocèse autour du pouvoir épiscopal.

Aux dires de son successeur Robert Céneau, il augmenta considérablement les revenus du siège d'Avranches, ce qui paraît vraisemblable au vu de l'exubérance de ses générosités. Sa cathédrale lui devait un jubé décoré de statues, fermant le chœur, les chapelles latérales de la nef, l'agrandissement de la chapelle axiale consacrée à la Vierge, en plus de beaux ornements et d'une salle destinée à la réunion des synodes montrant sa sollicitude envers une institution qui rassemblait autour de lui et de ses officiers les curés de son diocèse. Il fit reconstruire à la fois le manoir épiscopal de la ville et la demeure campagnarde des successeurs de saint Aubert, Le $\operatorname{Parc}^{26}$. Dans cette seconde propriété, il créa un logis à la mode du temps: deux bâtiments en équerre s'adossaient à la muraille, une galerie à arcades en plein cintre, ouverte à la fois sur la cour et le jardin, occupant le rezde-chaussée de l'un d'eux ${ }^{27}$. À Savigny, il édifia le manoir abbatial ${ }^{28}$. Le codicille de son testament indique qu'il a dépensé au moins cinquante livres tournois dans son abbaye de Saint-Georges-du-Bois ${ }^{29}$. Ce goût des constructions ne l'éloignait pas de nombreux prélats de son temps, mais l'ardeur qu'il mit dans ce mécénat, malgré la modestie de ses revenus par rapport à d'autres évêques, montre une générosité de grande ampleur.

Peu de personnes peuvent, par l'influence qu'elles ont eue, conduire à une meilleure compréhension de Louis de Bourbon-Vendôme et de son testament. Il semble avoir su s'entourer d'officiers à la formation solide; les grades universitaires élevés caractérisent le clergé épiscopal et cathédral des diocèses de son époque, mais les théologiens prennent ici une place particulière: outre Jean Le Masson présent à ses côtés depuis les années 1490, Pierre Bouillon, docteur en théologie, l'accompagne dans ses visites en 1485 et porte en 1494 le titre de vicaire; si deux ans plus tard son official diocésain, Guillaume de Perrières, est docteur

25. Cette fonction de maître des novices apparaît particulière et peut-être récente puisque rémunérée directement par l'évêque-abbé. Le Masson était déjà vicaire général pour Savigny dans les années 1490: Beaurepaire, [sd], p. 31 et 45.

26. Dép. Manche, cant. La Haye-Pesnel, c. Sainte-Pience. Il ne reste rien aujourd'hui des constructions du Parc.

27. CASSET, 2010, p. 371-372. Selon cet auteur, il n'est pas impossible qu'il ait commandé des travaux à Saint-Philibert-sur-Risle.

28. Il ne semble pas en revanche avoir laissé beaucoup de traces dans son prieuré d'Épernon: LEDRU, 1899 , p. 293-340.

29. Il s'agit peut-être de travaux au logis abbatial, puisque celui-ci avait été construit au XVI ${ }^{e}$ siècle. 
en lois, l'archidiacre d'Avranches Nicolas Murdrac porte le grade de docteur en théologie $^{30}$. L'archidiacre Pierre Rodet, qui figure parmi les exécuteurs, reste un inconnu, sa présence tient peut-être davantage à sa dignité qu'à la force de ses liens avec l'évêque; il ne se trouve pas auprès de lui lors du testament, de même que trois autres exécuteurs, Jean Gueterot, Gilles Foucault et Pierre Villecoq, dont les deux derniers sont ses "dépensiers", de simples officiers donc, curés de paroisses, mais qui, ne portant pas le titre de maître, n'ont pas fait d'études à l'Université et n'accomplissent que des tâches de gestion ${ }^{31}$. Jean Bouhalle, son hôte en une maison du cloître de Saint-Martin de Tours au moment où il teste, se contente-t-il de loger le prélat lorsqu'il vient à Tours, ou cet accueil traduit-il une véritable amitié? La seconde hypothèse est la plus vraisemblable, car entre le cloître de Saint-Gatien et celui de Saint-Martin, sans compter des hôtels bourgeois ou nobles, la cité ligérienne ne manquait pas d'autres lieux qui auraient pu le recevoir. Bouhalle, présent à la dictée du testament, mais sans responsabilité dans l'exécution, sans doute parce que trop éloigné d'Avranches et des contrées où des biens de l'évêque se trouvent, appartient à une famille très influente à Tours, qui compte d'abord Guillaume, tailleur de la monnaie, et Jean, docteur in utroque, serviteur du roi René, personnalité majeure de l'Église d'Angers au milieu du XV ${ }^{\mathrm{e}}$ siècle, régent et chancelier de l'université, vicaire épiscopal, qui accumule avant sa mort en 1465 les dignités et prébendes à Tours, Angers et Rennes ${ }^{32}$. À la génération suivante, un autre Jean, licencié en lois, juge de Touraine en 1482-1483, épouse Jeanne Briçonnet et par là se trouve être l'oncle du cardinal Guillaume Briçonnet et de son frère Robert, archevêque de Reims. L'hôte de l'évêque d'Avranches en 1510 cousine donc, de manière plus ou moins éloignée, avec ces grands personnages que sont les Briçonnet ${ }^{33}$. Les Bouhalle cultivent les lettres et la vie spirituelle, l'ecclésiastique d'Angers lit Cicéron, Cassiodore, Isidore de Séville et saint Jérôme, le juge de Touraine possède la célèbre Vie de Jésus de Ludolphe le Chartreux ${ }^{34}$. En s'installant auprès de Saint-Martin de Tours, Louis de Bourbon satisfait aussi son attirance envers les collégiales séculières, tradition familiale des comtes de Vendôme protecteurs de la collégiale Saint-Georges, reprise par son demi-frère Louis à Champignysur-Veude ${ }^{35}$.

L'évêque d'Avranches apparaît surtout proche de ce demi-frère, légitime de naissance, qui porte le même prénom, prince de La Roche-sur-Yon et seigneur de Champigny-sur-Veude, deux seigneuries qu'il tient de sa mère Isabelle de Beauvau, comte de Castres et seigneur de Châteauroux. Présent auprès de lui lorsqu'il teste, il en fait son exécuteur principal alors que ne figure pas le chef de la famille, Charles, futur duc de Vendôme, fils de leur frère François qui est

30. BeAurepaire, [sd], p. 31 et 49 .

31. Foucault est curé de Croslon (auj. Crollon), dép. Manche, canton de Ducey, et Villecoq, de Saint-Loup, dans le canton d'Avranches.

32. MATZ et COMte, 2003, p. 268.

33. Chevalier, 1975, p. 280, note 26. Chevalier, 2005, p. 419.

34. Matz et Comte, 2003, p. 36. Chevalier, 1975, p. 558, note 197.

35. Dép. Indre-et-Loire, cant. Richelieu. 
mort en Italie en 1495. Le prince est un homme pieux: en 1499, à 26 ans, il fonde la collégiale de Champigny-sur-Veude, où il prévoit en 1507 d'être enterré, mais dont il ne pourra cependant commencer les travaux que bien plus $\operatorname{tard}^{36}$. Il éprouve une grande vénération pour leur ancêtre saint Louis. La force des liens entre les deux frères conduit à supposer une possible influence de l'évêque sur le prince, nettement plus jeune que lui.

Il guida de même ou au moins soutint la courageuse action réformatrice de deux demi-sœurs plus jeunes, placées à la tête de communautés monastiques de premier plan comme il seyait à leur naissance. Renée, abbesse de la Trinité de Caen en 1491 puis la même année de Fontevrault, appelant sa cadette Isabelle comme grande prieure, avant qu'elle lui succédât à Caen en 1495, rétablit la clôture dans l'abbaye ligérienne et fit entreprendre de grands travaux aux bâtiments. En 1505 il vint à Fontevrault recevoir de Renée et de toutes les religieuses de chœur le vœu de grande clôture, et bénir Isabelle, qui elle aussi restaura à Caen la discipline monastique et fit élever des grilles de $\mathrm{fer}^{37}$. Sans doute pensait-il, comme son primat le cardinal Georges d'Amboise, que le retour à une plus grande austérité des communautés religieuses constituait un élément essentiel de la réforme de l'Église de France.

\section{Les ultimes dispositions}

Bien que passé à l'article de la mort et non trace d'une méditation mûrie et longuement élaborée, son testament exprime avec netteté un ensemble cohérent de choix spirituels. Jésus et Marie, en une dénomination chargée d'intimité, sont placés en exergue, mais le Dieu créateur, la Passion et la Rédemption $\mathrm{du}$ Christ manquent, bien que leurs mentions apparaissent souvent dans les formules d'invocation et de recommandation des autres testaments. La Trinité, pourtant patronne de l'abbaye de Savigny, s'estompe dans le terme "Altissimo». La dévotion envers les saints ne prend guère d'ampleur, alors que de véritables litanies, hiérarchisées et méditées, expriment souvent les affinités spirituelles des testateurs. Ne viennent à l'esprit de Louis de Bourbon que Michel, archange $\mathrm{du}$ Jugement mais surtout patron d'un Mont qui identifie profondément le diocèse d'Avranches, et André, patron de sa cathédrale, pas même ce saint roi dont il porte à la fois le sang et le nom et dont au contraire son frère marquera fortement la présence, par la statuaire notamment, à Champigny-sur-Veude: l'évêque inspire le texte plus que le Bourbon réduit par la proximité de la mort à l'état de pauvre pécheur. Les mérites de tous les citoyens de la cour des Cieux assureront la rémission de ses fautes: la communion des saints ici présente suscite sa confiance apaisée. Dans la réparation des torts commis, mise en place par le testament, les fautes s'effacent: Louis de Bourbon, imprégné de la vision médiévale de la confession exigeant à la fois l'aveu et la réparation, souhaite

\footnotetext{
36. Noblet, 2009, passim, notamment p. 29.

37. Dictionnaire d'Histoire..., 1938, X, col. 134-135. Gallia christiana, XI, col. 435-436.
} 
compenser financièrement les éventuelles faiblesses de la gestion de ses bénéfices, et prendre à son compte une amende infligée à son promoteur Jean de Cabriolle dans la défense des droits épiscopaux. Quoique ne présentant pas non plus d'invocations de saints, le testament de Geoffroy Herbert, évêque de Coutances, daté du $1^{\text {er }}$ janvier 1510 , expose des caractéristiques bien différentes ${ }^{38}$ : son long préambule riche d'allusions à des paraboles évangéliques, à l'Apocalypse et à saint Jérôme, travaillé par un pardon qu'il offre lui-même à ceux qui l'ont offensé, exprime une réflexion sur l'âme, créée à l'image de Dieu, retirée de la captivité de Babylone au prix des souffrances et de la mort du Rédempteur et consacrée spécialement pour le servir en cette vie. Ce confrère et voisin de l'évêque d'Avranches, conscient lui aussi de l'élévation très particulière dont l'épiscopat l'a revêtu, recommande son âme pour qu'elle soit reçue dans le sein d'Abraham, comme aussi le troupeau à lui confié, références à deux éléments culturels complètement absents du texte de Louis de Bourbon-Vendôme, une vision assez précise de l'au-delà aux origines très anciennes et un souci pastoral qui marque l'élite ecclésiastique de la France du Nord depuis le début du $\mathrm{XV}^{\mathrm{e}}$ siècle.

Les dignités détenues et les circonstances de la mort déterminent pour Louis de Bourbon le choix des lieux d'inhumation, non l'attachement particulier à telle communauté ou à tel sanctuaire: il n'attend d'intercession ni d'un bienheureux dont il se serait toute sa vie montré le dévot zélé, ni de moines ou de frères dont l'ardeur et les prières lui seraient apparues les plus efficaces. La localisation précise des sépultures ne fait référence à aucune relique ni à aucun autel et, dans ses fondations obituaires, il s'intéresse davantage aux processions qu'aux célébrations de l'eucharistie, ne finançant par exemple aucune chapellenie: le sacrifice du Rédempteur, renouvelé hic et nunc dans la messe, n’a pas pour lui l'efficacité première pour le salut que lui prêtent la plupart des fidèles de son temps. Il ne se connaît aucune responsabilité à l'égard de ses parents, ses lieux d'inhumation n'expriment aucune attache familiale ${ }^{39}$, les célébrations qu'il fonde n'ont pas la finalité habituellement déclarée du salut des ancêtres: épousant l'Église d'Avranches, il a quitté son père et sa mère ${ }^{40}$ et s'est fait le fils de ses prédécesseurs sur ce siège. Sa consécration épiscopale a effacé ses origines, jusqu'en l'illégitimité de sa naissance. Recevant les ordres et des bénéfices et dignités, il est entré dans la fraternité spirituelle de communautés cléricales: nulle angoisse de la mort ou des tourments de l'au-delà, la prière de celles-ci assurera

38. Ibid., XI, Instrumenta, col. 278-280.

39. Il aurait pu par exemple demander une inhumation auprès de ses grands-parents, de son père ou de son demi-frère ainé François à Saint-Georges de Vendôme: ce lieu paraît réservé à la branche ainée, ce pourquoi sans doute son demi-frère Louis se fit inhumer à Champigny-sur-Veude, mais il en avait été chantre et en général le clergé d'une église pouvait trouver sépulture entre ses murs. Il avait manifestement conservé des attaches en cette ville de son enfance: en 1483 il y achète pour 90 livres une maison, puis l'année suivante le quart d'une autre, pour 10 livres. En 1505, il abandonne une rente sur une maison de la ville contre un jardin, avec un chapelain de cette collégiale. En 1491, l'official de Vendôme, Jean de La Rougeraye, tient un canonicat dans la cathédrale d'Avranches. Chartres, Arch. dép. Eure-et-Loir, G 228, 240, 241, 262.

40. Matthieu, 19, 5 . 
le souvenir de ses générosités pour le développement du service divin comme les constructions et les œuvres d'art celui de ses largesses pour le rayonnement de son siège. Les premières sont d'ailleurs plus modestes que les secondes: le revenu perpétuel laissé à Saint-Martin de Tours devra être ténu, quarante sous par an à Savigny montrent la faible valeur qu'il attribue à la prière des moines cisterciens, les cinq ou dix livres dépensées par jour de transport du corps incluent les prières et le luminaire comme le salaire des convoyeurs. Certes mille deux cents livres financeront douze obits à la cathédrale d'Avranches; cette somme permettra une certaine magnificence, mais la dépense n'a rien de flamboyant par rapport à d'autres cérémonies mémorielles pour un évêque, aucune perpétuité n'est instituée et vient immédiatement après l'offrande à fin liturgique le mécénat de la fonte d'une cloche voulue notable et somptueuse. Les autres mille deux cents livres, à la disposition du principal exécuteur, augmentées d'éventuels reliquats, doivent assurer les compensations pour défaut d'entretien du temporel que, dans ses autres bénéfices, les successeurs du prélat pourraient de droit réclamer à son exécution. Toutes ces charités, à quoi sa dignité l'oblige, limitées au total, trahissent une fortune sans doute obérée par les dépenses de constructions qu'il a engagées ${ }^{41}$. Surtout, elles ne sauraient à ses yeux constituer un mérite pris en compte au jour du Jugement. L'imprécision et la faiblesse des demandes d'anniversaires, qui se retrouvent, poussées jusqu'à l'absence, dans le testament de Geoffroy Herbert, la liberté laissée aux exécuteurs en ce domaine, le terme, très rare, de subvenite, qui évoque en écho le secours comme le souvenir, pour définir ce qu'il souhaite à Saint-Martin de Tours, révèlent le passage d'une mémoire spirituelle et salutaire, fortement centrée sur la messe, caractéristique des décennies précédentes, à l'édification d'une gloire posthume, d'inspiration plus humaniste. Louis de Bourbon n'adhère cependant pas à une attitude théologiquement critique envers les prières pour les morts, présente dans de nombreux courants hétérodoxes: au contraire, un rare vestige de ses décisions synodales accorde en 1496 une indulgence de quarante jours aux prêtres qui reprendront la coutume de dire chaque jour en Carême un office des défunts ${ }^{42}$. Dès lors, quelles considérations le conduisent-elles à des choix différents pour lui-même? Pourquoi quête-t-il une gloire dont il faut s'interroger sur la destination véritable: sa personne ou la dignité épiscopale qu'il a reçue?

L'attention portée au corps, quoique désigné comme ergastula, un terme savant qui trahit peut-être les lectures humanistes de ce prélat, contraste avec l'insouciance du sort de l'âme: les prières accompagnent les étapes du transport du cadavre et sont célébrées en sa présence, avant de faire mémoire non de la personne de l'évêque, corps et âme réunis, mais des inhumations des différents éléments du corps divisé immédiatement après le décès. Le séparant en trois,

41. Geoffroy Herbert répartit au contraire entre dix et vingt mille livres, au profit de 22 serviteurs et servantes et surtout de membres de sa famille. Les seules dépenses de funérailles de l'archevêque de Rouen Robert de Croismare, en 1493, montent à trois mille livres tournois (Rouen, Arch. dép. Seine-Maritime, G 2144, fol. 330).

42. Beaurepaire, [sd], p. 45. 
Louis de Bourbon aura trois sépultures, Saint-Martin de Tours auprès duquel il ferme les yeux, l'abbaye de Savigny et la cathédrale d'Avranches ${ }^{43}$. Boniface VIII, en 1299, a pourtant fermement condamné le démembrement des corps. Le pape, reprenant la position du théologien parisien Godefroid de Fontaines, a en effet jugé atroces et inhumaines les pratiques d'éviscération et d'ébullition des cadavres afin d'en détacher les chairs et les os: l'unité du corps humain doit être préservée jusqu'à la Résurrection, le cardinal Le Moine affirmant au même moment que, modelé à l'image de la beauté céleste, il ne peut être entaché ni défiguré, contre les théologiens thomistes pour qui la dépouille, matière séparée de sa forme, n'est plus un homme ${ }^{44}$. Ce démembrement n'avait pourtant rien d'inhabituel, à partir des années 1270 de nombreux princes, souvent issus du lignage royal, avaient exprimé ce choix dans leur testament ${ }^{45}$. Si le roi Jean II fait intégralement inhumer son corps à Saint-Denis, Charles V le divise en trois, ossements en la vénérable abbaye royale, cœur à la cathédrale de Rouen et entrailles à l'abbaye de Maubuisson, près de la tombe de sa mère ${ }^{46}$. Par la suite, aussi bien Charles VI, Charles VII que Louis XI furent inhumés en entier, mais Charles VIII fit prélever son cœur pour le placer près de son père dans la collégiale Notre-Dame de Cléry ${ }^{47}$. Les ducs de Bourbon Jean II et Pierre II, décédés respectivement en 1488 et 1503 , disposent aussi de tombes multiples ${ }^{48}$. Dans la propre lignée de l'évêque d'Avranches, son grand-père Louis, comte de Vendôme et vidame de Chartres, a souhaité l'enterrement de son corps dans la collégiale Saint-Georges du château de Vendôme et celui de son cœur dans la chapelle dite de l'Annonciation à la cathédrale de Chartres ${ }^{49}$. En général, la sépulture du corps exprime la dimension sociale et publique de la personne, celle du cœur traduisant un attachement plus familial et intime: si le corps d'Anne de Bretagne, morte en 1514, trouva place à Saint-Denis, son cœur, enfermé dans un joyau d'or, fut inhumé aux Carmes de Nantes près du tombeau de ses parents ${ }^{50}$.

Les menaces de Boniface VIII, privation de sépulture chrétienne du corps maltraité et excommunication dont le pardon lui est réservé pour les exécutants, semblent avoir davantage marqué les ecclésiastiques, à moins que la consécration reçue efface la dimension privée de leur personne: le démembrement est exceptionnel dans les testaments des prélats, Geoffroy Herbert ne l'envisage nullement, par exemple. Testant en 1404 dans son château de Champforgueil, tout près de

43. La cathédrale n'est pas le lieu d'inhumation obligatoire de l'évêque, le droit canon n'impose rien, les choix de sépultures sont personnels et donc variés: Jourd'HeUIL, 2009, p. 256.

44. Paravicini-Bagliani, 2003 p. 231-238.

45. Gaude-Ferragu, 2005, p. 318.

46. BROWN, 1981, p. 261.

47. Bande, 2009, p. 154. Gaude-Ferragu, 2005, p. 324.

48. Gaude-Ferragu, 2005, p. 321.

49. ANSELME, 1726, I, p. 322.

50. BANDE, 2009, p. 177. L'inhumation des entrailles paraît quant à elle avoir exprimé parfois la sensibilité spirituelle du testateur: Jeanne de Bourgogne, épouse de Philippe VI, avait demandé l'inhumation de son corps à Saint-Denis, en tant que reine, de son cœur à Cîteaux auprès de ses ancêtres de la maison capétienne de Bourgogne, et de ses entrailles en l'abbaye des Clarisses du Moncel près de Pont-Sainte-Maxence: Gaude-Ferragu, 2009, p. 390. 
sa cité de Chalon-sur-Saône, Olivier de Martreuil, qui élit sépulture dans une abbaye cistercienne de son diocèse, Maizières, prévoit le cas où il mourrait au loin: son corps devra être enterré dans une collégiale ou une honnête église du lieu, jusqu'à ce que la terre consume la chair et que les os puissent être séparés et transportés; il interdit explicitement que le cadavre soit découpé en morceaux ou bouilli ${ }^{51}$. Le cardinal Jean de La Grange, évêque de Tusculum, demande cependant en 1402 que ses ossements soient transportés secrètement dans le tombeau qu'il a fait préparer dans la cathédrale d'Amiens, son ancienne épouse, le reste de son corps, c'est-à-dire la chair et les entrailles, recevant une sépulture dans la collégiale Saint-Martial d'Avignon; il tient à préciser qu'il a obtenu pour cela une autorisation spéciale du pape ${ }^{52}$. En 1461, l'évêque Guillaume de La Tour souhaite que son corps soit inhumé devant l'autel de la chapelle Saint-Jean-l'Évangéliste de sa cathédrale de Rodez, qu'il a dotée et ornée, son cœur étant enseveli dans le sanctuaire de la collégiale de Salles-Curan, qu'il a fondée $e^{53}$. Du cardinal Georges d'Amboise, mort à Lyon en mai 1510, les entrailles furent inhumées sur place, près du maître-autel de l'église des Célestins, le corps recevant l'abri du grand tombeau de sa cathédrale de Rouen ${ }^{54}$. Après Louis de Bourbon, l'archevêque de Sens Tristan de Salazar ( $†$ 1519) a fait déposer son cour dans le tombeau de ses parents au prieuré grandmontain de Macheret, en Champagne, ses entrailles dans la chapelle Saint-Laurent du palais des archevêques à Sens, et son corps dans la cathédrale ${ }^{55}$. L'évêque d'Avranches fut sans doute le premier prélat à avoir souhaité une tripartition, à joindre le cœur aux intestins, et surtout à demander une décapitation, ce dont on ne trouve pas d'autres traces, les fragmentations princières séparant le cœur, les entrailles et le corps, pour Charles V et les ducs Louis I ${ }^{\text {er }}$ et Louis II d'Anjou par exemple ${ }^{56}$.

La réunion du cour aux viscères sous une lame de cuivre «in modum figure cordis", à Saint-Martin de Tours, ne témoigne pas d'une volonté de dévalorisation: l'évêque reprend la pratique du tombeau où cet organe reçoit une représentation propre, tenu dans la main du gisant pour Charles V à la cathédrale de Rouen ou sa belle-mère Isabelle de Valois, femme du duc Pierre I ${ }^{\text {er }}$ de Bourbon, en 1380 également, en son tombeau de Souvigny, ou encore, et c'est peut-être la source d'inspiration de Louis de Bourbon, une plaque en forme de cœur incrustée dans le pavage pour le roi René dans l'église des Carmes d'Aix-en-Provence ${ }^{57}$. Quant au détachement de la tête, l'exemple de celle de son ancêtre saint Louis, pour laquelle Philippe le Bel commanda dès 1299, peu après la canonisation, un chef-reliquaire, inspira peut-être l'évêque d'Avranches, quoique pour la translation solennelle à la Sainte-Chapelle du palais à Paris, le

51. Paris, Arch. nat, X 1a 9807, fol. 146v-150.

52. Paris, Arch. nat., $X$ 1a 9807, fol. 70v-78. La séparation de la chair et des os implique de faire bouillir le corps après éviscération, donc des pratiques clairement condamnées en 1299.

53. BALUZE, 1708, II, p. 726-727.

54. Funérailles..., 1864.

55. TABBAGH, 2010, p. 198.

56. Tous deux firent inhumer leurs entrailles à Saint-Martin de Tours: GAUdE-Ferragu, 2005, p. 319.

57. Ibid., p. 329-330. 
17 mai 1306, le roi n'eût pu obtenir la totalité du chef, les dents et la mâchoire inférieure étant restées à Saint-Denis ${ }^{58}$. Logiquement, Louis de Bourbon a voulu donner la forme d'une tête au tombeau de Savigny, mais la présence d'une mitre charge ce choix d'une autre signification, d'autant plus qu'en cette église il souhaite lier cette sépulture et son obit à ceux de son prédécesseur Jean ${ }^{59}$ : son chef mitré constitue la figuration de la dignité éminente qu'il a reçue; évêque, il a été la tête du corps spirituel que constituait l'Église d'Avranches, comme le Christ est la tête de l'Église universelle. Ces tombeaux, constitués de simples plaques de métal et non de monuments de marbre, ne s'accompagneront d'aucune épitaphe: le souvenir ne requiert pas l'écrit, l'appel à la prière des passants n'est pas nécessaire. Voué à la résurrection au jour du Jugement, le corps mérite des honneurs en cette paisible attente, sous forme de processions, et des prières modérées, mais ne peut soutenir les suffrages à finalité salutaire. Plus profondément, le démembrement, la mémoire des inhumations, les tombes figuratives témoignent d'une volonté d'élévation de ses restes en reliques: ce sont les corps saints que l'on a morcelés depuis longtemps, leurs translations, élévations, inventions qui donnent lieu à des fêtes anniversaires, les reliquaires topiques leur sont destinés. Comme le montre aussi sa volonté du repos de son corps parmi ses prédécesseurs évêques d'Avranches, que son testament qualifie de sancti patres, Louis pressent que la consécration épiscopale l'a placé parmi les Pères dans le Christ, donc parmi les saints. Elle le dispense à ses propres yeux d'une quête de sanctification par un comportement particulier, fait de mortifications imposées, de charités affirmées ou d'humiliations recherchées, qui inspira au contraire quelques autres évêques de son temps ${ }^{60}$. Sa dignité, qui n'exige à ses yeux nulle accumulation de sacrifices méritoires, l'introduit à sa mort dans la cour des Cieux, son exaltation au sein de l'Église militante préfigurant sa gloire dans l'Église triomphante, sous la seule condition d'un exercice exact des responsabilités qui lui incombent ${ }^{61}$. La certitude d'être déjà sauvé estompe pour lui la recherche d'intenses prières poursuivies jusqu'à la fin des temps comme elle permet la transformation de son cadavre en reliques. Dans leurs tombeaux modestes en des lieux écartés et fermés, ses restes ne doivent cependant pas devenir des supports de dévotion pour les fidèles, il n'attend nulle invocation ni ne prétend à aucun pouvoir

58. Brown, 1980, p. 175-182.

59. On ne voit pas de quel évêque il peut s'agir: cinq prédécesseurs de Louis de Bourbon ont porté le prénom de Jean depuis la fondation de Savigny en 1112, ils sont inhumés l'un, Jean La Mouche, en l'abbaye des Prémontrés de La Lucerne, un autre, Jean de Vienne, à la cathédrale de Reims, le troisième, Jean Hautfuné, en l'abbatiale Saint-Ouen de Rouen, de même que Jean de Saint-Avit, Jean Boucart trouvant quant à lui place dans la cathédrale d'Avranches. En revanche, la Gallia Christiana indique que le cœur de Louis de Bourbon fut inhumé à Savigny avec les os de l'évêque d'Avranches Guillaume d'Osteilley (1210-1236).

60. Voir les exemples donnés par MATZ, 2010, p. 249-264.

61. L'attitude de Geoffroy Herbert est plus ambiguë: il recommande son âme pour qu'elle soit placée avec les patrons de l'Église de Coutances, donc ses prédécesseurs qu'il imagine spontanément comme sanctifiés, mais élit sépulture dans le chœur de sa cathédrale, à gauche du maître-autel, sous les reliques des saints placés en ce lieu, des saints universels sans lien avec l'Église de Coutances sans doute, dans un choix beaucoup plus traditionnel d'inhumation ad sanctos donc. 
thaumaturgique, il efface sa personne et sa mémoire derrière l'éclat de sa dignité tant dans l'œuvre de mécénat que dans la promotion post mortem des parties de son corps inhumées dans les sanctuaires.

L'originalité des ultimes volontés de Louis de Bourbon, en particulier la séparation de la tête et du corps, et des conceptions qui les soutiennent, a fait reculer ses exécuteurs. Une note marginale de la copie française du testament indique que «Madame» consulta la Sorbonne et que les théologiens refusèrent la sépulture d'une tête détachée ${ }^{62}$. Lorsqu'en 1779 on ouvrit sa tombe de la cathédrale, dans la chapelle axiale où reposent d'autres évêques depuis le XIII ${ }^{e}$ siècle, la tête était attachée au corps et encore garnie de cheveux ${ }^{63}$. Dans l'Église, la première, en qui s'incarne éminemment le Christ, ne peut être séparée du second, c'est-à-dire des fidèles. Le cœur de l'évêque aurait été inhumé à Savigny, aux dires de toute la tradition historiographique, mais il y avait bien un monument funéraire à Saint-Martin de Tours, dans le chœur, proche du second pilier, face à la stalle du chantre $^{64}$ : sans doute recouvrait-il les seules entrailles.

Les trois transcriptions qui suivent, de l'instrument notarié du testament, en latin, de sa copie en traduction française, et du codicille qui la suit, n'ont pas pour but la connaissance des ultimes dispositions de Louis de Bourbon-Vendôme, déjà largement explicitées dans l'étude qui précède. Elles visent à permettre une approche des pratiques d'écriture, laissée à la liberté du lecteur, dans les perspectives qu'ouvrent les recherches sur toutes les mises en forme d'un document et qu'a illustrées par exemple la publication des cédules du vote de la soustraction d'obédience de l'Église de France au pape Benoît XIII en $1398^{65}$. En conséquence, les éléments habituellement recommandés d'une modernisation du texte destinée à faciliter sa compréhension et l'étude de son contenu, logique dans des éditions de sources où le document n'est précédé que d'une courte analyse, ont été écartés. L'orthographe de la source a été respectée, y compris dans l'emploi des majuscules et dans la ponctuation, aussi erratiques qu'elles puissent paraitre, aucune apostrophe ni aucun accent n'ont été ajoutés, l'article n’a pas été séparé du substantif lorsqu'il ne l'était pas dans la source, le «i» n'a pas été transformé en «j» dans les pronoms

62. La personnalité féminine qui intervient ainsi ne pouvant être que d'un rang supérieur au principal exécuteur, le prince de la Roche-sur-Yon, s'offrent à une tentative d'identification la reine Anne de Bretagne, que l'évêque d'Avranches fréquenta certainement sur les bords de la Loire, ou plutôt Anne de Beaujeu, figure éminente de la famille de Bourbon, plus éloignée de lui par la résidence mais plus proche par le sang. Les rares études d'archéo-anthropologie sur la question du traitement des corps immédiatement après la mort montrent l'existence de techniques de sciage de la calotte crânienne pour extraire le cerveau, mais non de détachement de la tête pour la séparer du tronc: Charlier et GeORges, 2009, p. 419.

63. Le Héricher, 1980, p. 19. D’autres évêques avaient été inhumés dans le chœur, en particulier son prédécesseur immédiat Jean Boucart, confesseur de Louis XI.

64. LELONG, 1986, p. 109.

65. Millet et Poulle, 1988. 
latins. L'utilisation d'une plume épaisse par le scribe a été rendue par des caractères gras. Les abréviations ont cependant été développées selon l'orthographe actuelle et la volonté de permettre l'abord de la mise en page a entraîné l'introduction de «/» à la fin de chaque ligne et la foliotation de la copie française, la présentation en paragraphes de cette dernière et du codicille étant évidemment maintenue. Les transcriptions numérisées de sources, si elles se tiennent au plus près d'elles et si elles deviennent le support d'observations quantifiées, pourraient contribuer à la compréhension des choix orthographiques et des gestes graphiques, notamment pour déterminer dans quelle mesure les permanences observées trahissent l'existence d'habitudes partagées, vraisemblablement évolutives, et de repérer des modalités et des lieux d'apprentissage, pour les notaires par exemple. La progression des normes orthographiques doit pouvoir être précisément étudiée, puisqu'elle exprime directement la valorisation culturelle du geste d'écriture.

Rouen, Arch. Dép. Seine-Maritime, G 8680, instrument public original sur parchemin.

\section{$\dagger$ \\ $\dagger$ Jhesus Maria $\dagger$ \\ $\dagger$}

In nomine Sancte et Individue trinitatis patris filii et spiritus sancti amen. Noverint universi Quod Anno domini millesimo quingentesimo decimo indictione decima tercia die vero decima septima mensis / octobris pontificatus sanctissimi in christo patris et domini nostri domini julii divina providentia pape secundi Anno septimo in nostrum notariorum publicorum venerabiliumque dominorum testium infrascriptorum presentia presens et personnaliter constitutus Reverendus in christo pater et dominus dominus ludovicus / de borbonno episcopus abrincensis in domo canoniali venerabilis viri magistri johannis bouhale insignis ecclesie beatissimi Martini turonensis ad Romanam ecclesiam nullo medio pertinentis canonici in claustro ecclesie predicta sita. egretudine corporali detentus et lecto decumbens/mente tamen sanus et intellectu vigens volens anime sue consulere et pro eius salute de rebus et bonis suis testamentarie disponere Omnibus melioribus modo via jure causa et forma quibus melius et efficatius potuit et debuit potestque et debet suum/testamentum suamve ultimam voluntatem fecit condidit ordinavit et declaravit in modum qui sequitur. In primis Animam suam postea quam vocante domino a carnis ergastulo soluta fuerit Altissimo almeque genitrici sue beatissime Marie Matri misericordie sanctis archangelo / Michaeli et Andree apostolo sub cujus nomine dedicata est dicta Abrincensis ecclesia totique supernorum civium curie celesti commendavit Quorum meritis et interventione Remissionem peccatorum obtinere et penas ultionis extreme evadere mereatur. Item voluit/ et ordinavit quod omnia et singula debita sua legitime recognita fideliter ac primitus et principaliter solvantur per manus dominorum executorum suorum infranominandorum. 
Item declaravit voluit et ordinavit quod si contingat ipsum turonis ex hac infirmitate / decedere illico vita functo eius cor et intestina a corpore suo separentur. et in ecclesia predicta beatissimi Martini turonensis loco per dominos dicte ecclesie in eadem si eis placuerit eligando et ordinando inhumentur. et quod super huiusmodi cordis et intestinorum sepultura/scutum seu lamina cuprea in modum figure cordis formanda apponatur qua die dicte sepulture seu inhumationis fiat et celebretur in eadem ecclesia beatissimi Martini unum solenne servicium de defunctis. Item et insuper in memoriam perpetuam / sepulture cordis et intestinorum predictorum ac pro anime eius remedio et salute voluit et ordinavit quod domini executores sui presentis testamenti seu ultime voluntatis infranominandi acquirant quendam tenuem redditum perpetuum pro fundatione unus subvenite / per dominos dicte ecclesie singulis annis perpetuis futurisque temporibus die tali quod cor et intestina predicta inhumabuntur collegialiter et processionaliter super eadem sepultura si eis placuerit aut alias pro libito voluntatis et ordinationis eorundem dominorum in fine/servicii de defunctis in ipsa ecclesia celebrandi seu alio aptiori et convenientiori die per eos eligando Item voluit et ordinavit quod corpus suum sex dierum spacio si commode fieri possit ad monasterium suum de Savigniaco Cisterciensis ordinis sue diocesis abrincensis / deferatur et conducatur ac ibidem in ecclesia dicti monasterii aliquantis diebus requiescendum deponatur. Item et in conductione dicti sui corporis e Turonis ad monasterium prefatum de Savigniaco voluit et ordinavit quod singulis diebus in itinere corpore/predicto in sero hospitio reddito in ecclesiis locorum quiescendum et pernoctandum sine pompa reponatur et mane facto ante recessum fiat in ecclesia servicium de defunctis corpore predicto presente. Item et ordinavit idem dominus testator quod singulis diebus/predictis summa decem librarum turonensium in servicio ecclesiastico luminari et expensis personarum dictum corpus suum conducentium et concomitantium expandatur Item et dicto suo corpore ad huiusmodi monasterium de Savigniaco delato et ibidem applicato ac in illius/ ecclesia collocato voluit declaravit et ordinavit idem dominus testator quod adveniente die opportuno eiusdem sui corporis caput ab eodem separetur ac inhumetur in ecclesia predicta juxta aquilam chori dicte ecclesie ad latus sepulture quondam bone memorie Johannis/ eiusdem Abrincensis episcopi predecessoris sui quodque super dicti capitis sepulturam fiat et superponatur quedam parva tumba erea in modum capitis cum mitra et legatur obitus dicti domini testatoris annuatim unacum obitu dicti episcopi ibidem sepulti. Et quod per dictos suos / executores aliquis redditus acquiratur singulis annis persolvendus usque ad summam quadraginta solidorum turonensium qui redditus ad voluntatem abbatis et conventus dicti monasterii pro commemoratione dicti obitus exponetur. Item voluit et ordinavit dictus / dominus testator quod die sepulture eiusdem sui capitis celebretur in ecclesia dicti monasterii per religiosos eiusdem unum solenne servicium de defunctis et similiter singulis diebus quibus dictum corpus in ecclesia predicta stabit et quiescet fiat simile servicium. / Et quod per singulos ex dictis diebus quinque vel sex libre turonenses pro conventu luminari et sonatoria seu pulsatione campanarum expendantur Item et iis peractis voluit et ordinavit idem 
dominus testator quod huiusmodi corpus suum a dicto monasterio/ de Savigniaco ad abrincensem ecclesiam sponsam suam in qua suam eligit sepulturam transferatur et in eadem restituatur intra sepulturas sanctorum patrum predecessorum suorum secundum advisamentum et deliberationem dictorum suorum executorum et dominorum decani / et capituli ipsius Abrincensis ecclesie inhumandum. Item voluit insuper et ordinavit quod in dicta ecclesia abrincensi fiant et celebrentur per dominos de capitulo et alias personas ecclesiasticas eiusdem duodecim obitus seu servicia solennia diebus quindenis mensum/primi anni obitus in his non computato servicio solenni diei sepulture et inhumationis sue et hoc instar duodecim obituum similium alias in ecclesia abrincensi per quondam bone memorie dominum johannem boucart episcopum eiusdem abrincensis ecclesie ipsius domini testatoris / predecessorem fundatorum et quod dominus episcopus abrincensis pro tempore existens dictis obitibus interessendo plenariam distributionem quam propterea canonicus habebit percipiat. Pro quibusquidem obitibus ceterisque omnibus et singulis premissis eiusdem domini testatoris / funeralia concernentibus incipiendis fiendis et adimplendis voluit et ordinavit idem dominus testator quod dominus primus et principalis executor dicti sui testamenti infranominandus illico post decessum eiusdem domini capiat habeat et percipiat super singulis bonis/ipsius summam mille ducentarum librarum turonensium et si non sufficeret ampliorem prout dominatio sua melius considerabit et advisabit. Item et insuper pro potiori cautela et remedio ac salute anime eiusdem domini testatoris declaravit voluit et ordinavit quod/omnia et singula debita sua ante aliam quancumque pecunie expositionem fideliter et integraliter persolvantur secundum quod affirmabuntur deberi per dominos petrum villecoq egidium foucault et johannis daguenet eiusdem domini testatoris bonorum dispensatores quoniam ipsi / respective ipsius domini testatoris debita melius noverunt. Nichilominus tamen voluit et ordinavit quod prefati dispensatores reddant sua compota coram personis per antedictum dominum principalem executorem suum infranominandum ad hoc deputandis quibus minutis solutionibus / factis voluit et ordinavit dictus dominus testator quod summa mille ducentarum librarum turonensium exponatur secundum intentionem suam dicto domino principali executori suo seriose declaratam ad benefacta videlicet in beneficiis que tenuit retroactis temporibus in quorum regimine/timet idem dominus testator male se habuisse et usum fuisse Item quibus sic expositis factis et completis vult et intendit idem dominus testator quod de residuis bonorum suorum fiat liberalis distributio in fundandis obitibus suis perpetuis tam in ecclesia/ predicta cathedrali Abrincensi quam etiam in cappella ubi consueverunt cappellani et clerici ipsius ecclesie distributiones recipere Et si possibile sit fiat campana notabilis et sumptuosa que divinis obsequiis in festis maioribus triplicibus in quibus episcopus / divinum servicium facere et persolvere consuevit laudabiliter deservire possit Item dedit et legavit idem dominus testator magistro johanni de cabriolle Abrincensi promotori summam centum quinquaginta librarum turonensium in juvamentum ipsius / ad satisfaciendum de quadam emenda in qua per curiam scacarii normannie condemnatus fuit pro certo casu per dictum promotorem facto favore dicti 
domini testatoris. Credens ipse promotor sic faciendo eidem domino servicium impendere capiendam / super denariis recepte baronie Sancti Philiberti super rillam lexoviensis diocesis Novissime autem prefatus dominus testator executores presentis sui testamenti seu ultime voluntatis fecit elegit et constituit illustrem principem / et dominum dominum ludovicum de borbonio principem de Rocha super oyonam presentem et onus executionis huiusmodi testamenti in se assumentem primum et principalem executorem sui presentis testamenti et sub illius auctoritate potestate et/mandato venerabiles dominos et magistros Petrum Rodet Archidiaconum abrincensem johannem gueterot egidium foucault beate marie de crolonno et petrum villecoq sancti lupi parrochialium ecclesiarum eiusdem abrincensis diocesis rectores/absentes eisdem humiliter et benigniter supplicando quatinus onus et executionem dicti sui testamenti in se suscipere velint et dignentur Cuiquidem domino principi primo et principali et sub illius auctoritate mandato et/ordinatione ceteris huiusmodi sui testamenti supranominatis executoribus dedit et concessit omnimodam potestatem auctoritatem et facultatem faciendi agendi disponendi et ordinandi de sua sepultura funere et exequiis necnon expensis / funeralibus earundem prout supra disposuit et ordinavit idem dominus testator et quemadmodum melius advisaverint ac honestum et necessarium viderint pro qualitate sue dignitatis episcopalis et honore ac consuetudine dicte cathedralis ecclesie/abrincensis observatione et de omnibus et singulis in suprascripto suo testamento contentis dispositis ordinatis et legatis faciendi et ordinandi necnon eisdem suis executoribus plenam et liberam potestatem bona sua ubicunque existentia et in quibuscunque / rebus consistant capiendi petendi exigendi et recipiendi ipsaque vendendi distrahendi et alienandi ac creditoribus satisfaciendi Ceteraque que necessaria fuerint pro complemento huiusmodi sue ordinationis faciendi et exequendi Insuper voluit/ ordinavit et decrevit dictus dominus testator huiusmodi suum testamentum seu ultimam voluntatem valere jure testamenti et si jure testamenti valere non poterit quod valeat tamen jure codicillorum aut cuiuslibet alterius ultime voluntatis ac alias / prout melius fortius et firmius valere poterit de consuetudine seu de jure De et super quibus omnibus et singulis premissis idem reverendus dominus episcopus Abrincensis testator sibi suisque dominis executoribus et procutatoribus ac creditoribus / legatariis et aliis quorum interest, intererit aut interesse poterit quomodolibet in futurum fieri atque confici petiit unum vel plura instrumentum et instrumenta. Acta fuerunt hec in domo predicta canoniali ipsius magistri johannis / bouhale in dicto eiusdem ecclesie beatissimi Martini turonensis claustro sita sub Anno indictione mense die et pontificatu predictis. Presentibus ibidem venerabilibus viris magistris johanne bouhale prefato et matheo surdi presbiteris/turonensibus testibus ad premissa vocatis specialiter et rogatis

Suivent les souscriptions et paraphes de Guillaume du Moulin, prêtre de Tours, curé de Clamart au diocèse de Paris, notaire public d'autorité apostolique et scribe du chapitre de Saint-Martin de Tours et de Louis François, clerc du diocèse de Chartres, licencié en décret notaire public d'autorité apostolique. 
Paris, Arch. nat., $K 538 n^{\circ}$ 8, copie de la traduction française du testament, cursive du début du XVI siècle.

\author{
Jhesus Maria
}

[fol. 1r] Ou nom de la saincte et indivisee / Trinite le pere le filz et le / Sainct Esperit amen Saichent/tous que lan mil cinq cens et dix xiiie/indiction le xviie jour doctobre et lan/septiesme du pontificat de notre sainct/pere le pape Jule deuxiesme de/ce nom Es presences de nous notaires / et de messeigneurs les Tesmoings soubz/scripts present et personnellement establi/Reverend pere en dieu monseigneur loys / de Bourbon Evesque de Avranches/sain de pensee et bon entendement / detenu en infirmite Corporelle et / cousche au lit en la maison canoniale / de venerable personne monseigneur maistre jehan/bouhale chanoine en leglise monseigneur sainct / martin de tours situee ou cloistre deladite / eglise voulant conseiller son ame et/pourveoir a son salut et pource/dispouser de ses biens Testamentairement/ en la meilleur forme et maniere quil a peu [fol. 1v] Et deu Il a faict ordonne et declare / son Testament et derniere volunte ainsin / qui sensuit

I Premierement Il a commande son ame apres / quelle sera yssue de son corps a dieu le createur / a la glorieuse vierge marie sa mere mere de / misericorde a sainct michel larchange/Sainct andre lapustre ou nom duquel/ est fondee et dediee leglise davranches/son espouse Et generament a tous les saincts / de la court celestiel de paradis par / les merites et intervention desquelz il puisse / obtenir remission de ses peches et trader/les peines et vengences denfer

II Item il a voulu et ordonne que toutes et/chacunes ses debtes deuement recongneus soient/premierement et principallement payees par/les mains de messeigneurs ses executeurs cy dessoubz/nommez

III Item il a voulu declaire et ordonne que/ sil advient quil decede de ceste malladie en / ceste ville de tours que incontinant apres son/trespas ses cueur et intestines soient/separez et mis hors de son corps et enterrees/en ladite eglise monseigneur sainct martin au lieu [fol. 2r] Quil plaira a messeigneurs deladite / eglise et que sur la sepulture des cueur/ et intestines susdits soit mise et apousee / une lame de cuyvre en forme / et figure de cueur Item que le jour de la sepulture / diceulx soit fait ung service solennel des / Trespassez En icelle eglise

IV Item et en oultre en memoire dece/ et aussy pour le remede et salut $\mathrm{de} /$ son ame il a voulu et ordonne que messeigneurs/ses executeurs aquierent quelque tendre/ revenu perpetuel pour la fondacion dun/subvenite qui sera dit et celebre par/chacun an par messeigneurs deladite eglise / a tel jour que linhumation desdits cueur et/intestines ce fera sur la sepulture diceulx / et collegialement apres le service des trespasses/qui se fera ledit jour enladite eglise / ou aultrement ainsy que sera le bon plaisir/de mesdits seigneurs

$\mathrm{V}$ Item il a voulu et ordonne que son / corps soit mene et transfere en six jours / sy possible est et comodement il se/puisse faire a son monastere de savigne/de lordre de cisteaulx au diocesse davranches [fol. 2v] Et soit mis en leglise dudit monastere / pour repouser par certains jours 
VI Item et en conduisant sondit corps de / ceste ville de tours audit monastere de/ savigne il a voulu et ordonne que par chacun jour / en chemyn apres que ledit corps sera arrive/au logis sur le soir quil soit mis repouse/es eglises des lieulx sans pompe et/au matin avant partir soit fait ung service/en chacune eglise lesdit corps present

VII Item il a voulu et ordonne quil soit/despendu la somme de dix livres tournois par chacun / jour tant pour le service et luminaire dudit/ jour que pour les despens diceulx qui / conduiront et acompaigneront ledit corps

VIII Item et ledit corps arrive audit monastere / de savigne et remis en leglise dudit lieu/ledit testateur a voulu declare et ordon[ne] / que sa teste soit separee de son corps et/enterree en ladite eglise pres lengle du cueur/du couste de la sepulture de feu de/Bonne memoire jehan evesque davranches/son predecesseur et que sur la sepulture de la / teste soit myse et appousee une petite [fol. $3 \mathrm{r}$ ] tombe de cuyvre en forme de teste / avec la mictre et que lobit dudit/testateur soit leu par chacun an avec/lobit dudit evesque

[En face de ce dernier $₫$ dans la marge de gauche figure la note suivante dans une écriture différente:

La teste dudit feu/ seigneur evesque ne fut/pas separee du corps/ ne enterree audit/savigny pour ce que/Madame trouva par/advis de messeigneurs/de la Sorbonne cela/ ne se devoir fere]

IX Item et quil soit acquis par sesdits executeurs / aucun revenu montent a la somme de quarante / soubz tournois lequel revenu sera expense a la / voulunte des abbe et couvent dudit/monastere pour la commemoracion dudit obit

$\mathrm{X}$ Item il a voulu et ordonne que au/jour de la sepulture deladite teste soit celebre/en leglise dudit monastere ung service des/trepassez Et pareillement par chacun jour / que son corps repousera en icelle eglise/ soit fait pareil service Et sera expouse / et despendu par chacun desdits jours la / somme de cinq ou six livres tant pour le couvent/ que aussy pour le luminaire et sonnerie

XI Item et les chouses dessusdites faictes / et accomplies ledit seigneur testateur a voulu/et ordonne que son corps soit porte dudit/lieu de savigne a leglise davranches son/espouse en laquelle il a esleu sa sepulture/ et que en icelle eglise il soit inhume entre/les sepultures des bons saincts [fol. 3v] peres ses predecesseurs evesques dudit lieu/selon ladvis de mes dits seigneurs ses executeurs / et de messeigneurs les doyen et chappitre/de ladite eglise

Item il a voulu et ordonne que en icelle/ eglise davranches soient faictz et celebrez/par mes dists seigneurs les doyen chanoines et aultres/habituez en icelle douze services solennelz / par les quinziesmes jours des moys du / premier an de son obit en ce non comprins/le service solennelz de jour de son enterrement/et ce en la forme et maniere des douze/obitz aultreffoiz fait en ladite eglise/ pour feu de bonne memoire monseigneur/jehan boucart evesque dudit lieu et/que lesvesque qui sera pour le/temps en estant ausdits aubitz aura/et percevra paraille distribution / que ung [suscrit: chacun] chanoine dicelle eglise

Item et pource fere vieult et ordonne/que monseigneur son principal executeur/incontinent apres son trespas preigne/sur tous et chacuns ses biens la somme de xii cens / livres tournois tant pour le fait de ses ordonnances 
[fol. 4r] et enterrement dessusdits que pour lesdits obitz / et sy ladite somme ne suffist quil preigne/ telle somme quil advisera

Item et pour plus grand surecte de / lestat et salut de son ame ledit / testateur vieulx et entend que apres les [...]/ desadicte sepulture toutes et chacunes ses / debtes soient davant tout euvre payees / ainsy quelle seront affermees estre deues/par messeigneurs maistre pierre villecoq/gilles foucault et jehan daguenet / dispansateurs des biens dudit testateur/ [suscrit dans une écriture différente: pour ce quilz congnoissent mieulx les debtes et afferes dudit testateur] / et ce ne neantmoins Il vieult et ordonne / que les dessudits dispensateurs rendent/ leurs comptes davant les personnes / qui ace faire seront deputees par sondit/ principal executeur

Item apres que les menues debtes seront/payees ledit testateur a voulu et / ordonne que la somme de douze cens livres / soit expensee selon son intencion que il / a declaree a sondit principal executeur / Cestassavoir en bien fait aux benefices quil / a tenuz et possedez le temps passe selon / ladite declaration pour ce quil crainct/ne cestre pas gouverne en ladministracion/diceulx ainsin quil deust

[fol. 4v] Item et apres toutes et chacunes/les chouses dessusdites faictes parfaictes / et acomplies ledit seigneur testateur vieult/ et entend que du reste de ces biens / soit faict liberalle distribucion a fonder/obitz perpetuelz tant en ladite eglise / davranches que aussy en la chappelle en / la quelle les chappellains et clers / dicelle esglise ont acoustume recepvoir/distribucion et sil est possible qui soit fait / une cloche grosse et sumpteuse qui sonnera / et servira es grant festes triples esquelles / les evesques ont acoustume faire le / divin service

Item ledit seigneur testateur a donne et legue/a maistre jean de cabriolle promoteur/davranches la somme de cent cinquante/livres tournois laquelle il a ordonné luy/ estre baillee pour luy aider a payer/ladmende en laquelle il a este/ condanne par la court de leschiquier/de normandie pour certain cas commis par ledit/ promoteur en faveur dudit testateur cuidant/luy faire plaisir et service et seront prins / les deniers dicelle somme sur la recepte de la baronnie / de sainct philbert sur Rille au / diocesse de lisieux

[fol. $5 \mathrm{r}$ ] Item et pour toutes et chacunes les / chouses dessus declarees cestre faictes et / executees de poinct en poinct ledit seigneur/testateur a fait esleu nomme et ordonne/faict nomme et ordonne Puissant et/doubte seigneur et prince monseigneur loys / de bourbon Prince dela Roche suryon son/principal executeur present ace et prenant/la charge de actomplir ce present son testament/et soubz son auctorite puissance et/mandement venerables personnes maistres / Pierre Rodet archidiacre davranches/jehan gueterot gilles foucault cure de notre/dame de croulon et pierre villecoq cure/de sainct leu ou diocesse davranches / absens ses executeurs En leur supplyant quilz/veillent prendre la charge de lexecution / de sondit testament avec ledit seigneur et soubz/luy auquel seigneur prince premier et principal/et soubz son auctorite et commandement/aux dessus nommez il a donne et donne/toute puissance auctorite et facilete/ de faire de dispouser et ordenner de sa/sepulture obseque et funerailles et/aussy des despens [un mot rayé; suscrit: funeraires] ainsy [un 
mot rayé] / comme cy dessus il a ordonne et comme myeulx/ilz adviseront estre honneste et/necessaire selon la qualite de sa dignite [fol. $5 \mathrm{v}$ ] / [un mot rayé] / episcopalle lhonneur de ladite eglise / davranches et des coustumes observees es/sepultures des evesques dicelle et generallement de faire ordonner et executer/de poinct en poinct ce present son testament/selon le contenu en icelluy et aussy de/prendre et saisir tous et chacuns ses/biens en quelque lieu quilz soient les recepvoir/bailler quictances les vendre et aliener/et satisfaire aux crediteurs et de faire/toutes aultres chouses concernantes lexecucion/de present son testament

Item et a voulu et ordonne ledit seigneur testateur/ce present son testament valoir par droict/de testament et sy par droict de testament/ne peult valoir aumoins quil vaille par/droict de codicille ou autre [un mot rayé] derniere/volunte et aultrement ainsy que myeulx/valoir pourra et devra tant de droict / que de coustume desquelles chouses ledit seigneur/testateur nous a demande instrument pour/luy ses executeurs procureurs crediteurs legataires/et aultres pretendens interest fait et passe / ou cloistre deladite eglise monseigneur sainct [fol. 6r] martin de tours en la maison canonial/dudit maistre jehan bouhale les an/et jour que dessus Presents a ce ledit/maistre jehan bouhale et messire mace / le Sourd prebtre vicaire de leglise/ parrochiale de sainct suernyn dudit/tours Tesmoings a ce requis et/apellez

Paris, Arch. nat., $K_{538,} n^{\circ} 8$.

Copie en cursive du début du XVI ${ }^{e}$ siècle d'un codicille sous forme d'instrument public dont manquent dans la copie les souscriptions et signatures des notaires. La main est identique à celle de la copie de la traduction française du testament.

Jhesus Maria

[fol. 7r] In nomine domini amen Saichent / Tous que lan mil mil (sic) cinq cens/ et dix le xviie doctobre es presente/de nous notaires et des tesmoings / soubz scriptz present et personnellement/Estably reverend pere en dieu monseigneur/Loys de bourbon Evesque davranches/sain de pensee et bon entendement detenu/en infirmite Corporelle et cousche au/lict en la maison canoniale de monseigneur / maistre Jehan bouhale chanoyne de / leglise monseigneur sainct martin de tours situee/ ou cloistre de ladite eglise desirant pourveoir/au salut de son ame, Et ace que ses/Crediteurs soient deument et justement/ payez et satisfaictz a ceste come apres / que ledit seigneur ce jour duy a eu faict et passe/son testament et derniere volunte et / quil a declaire quil vieult et entend que / sondit testament sorte son plain et entier/effect, et que le contenu en iceluy soit par/sesdits executeurs deument execute / Icelui seigneur testateur de sa pure liberalle/ et franche volunte a dit ordonne / declare et confesse par forme de codicille/ les chouses qui sensuyvent

[fol. 7v] Premierement quil doit a honorable/homme martin moreau bourgeoys de/tours la somme de troys cens livres/ de prest 
Item a maistre jehan de cuyigy / cent cinquante livres tournois aussi de prest Item a denis bussereau cent livres de prest

Item a ses serviteurs pour leurs gaiges / troys cens cinquante livres ou environ

Item aux heritiers de feu maistre Guillaume / du boys quinze ou vingt livres tournois a / cause de despence faicte en la maison/dudict deffunct et a declare ledit testateur/dont il a deul et en crainct sa consience/quil a empeusche que lesdits heritiers nont/ este payez de la somme de cent livres / ou environ a eulx deue par feu monseigneur de vendosme

Item ledit seigneur testateur a voullu et / declaire que messire pierre villecoc/ rendra compte de la somme de iiic livres / aultrefois aprete par maistre pierre barbier [fol. 8r] Et prinse des mains de frere claude / de tinteville abbe de la ferte et semblament/le compte de certaines debtes dudit seigneur testateur que ledit seigneur a baillees par escript / a messire gilles foucault desquelles / il nen a eu entiere congnoissance

Item et en oultre a ordonne que ledit villecoq/et aussy ledit messire gilles foucault/rendront compte de leurs administracions/aux moindres fraiz quil ce pourra faire/ par davant Puissant et doubte seigneur monseigneur/Loys de bourbon prince de la Roche son / principal executeur ou par davant les / deputez de par luy

Item et a dit confesse et declare/ledit seigneur testateur que messire pierre / rodet archidiacre davranches luy a / bien et deument rendu compte / de ladministracion quil a eue de luy et / que il est deu audit rodet certaine / somme de deniers par larrest [suscrit: de sesdits comptes signes [un mot non lu]] de la main / dudit seigneur testateur

[fol. 8v] Item et vieult et entend ledit seigneur/testateur que ledit rodet et aussy jehan/gueterot prebtre soient et entendent a/l'audition des Comptes de messires / jehan caussin scelleur davranches / Symon Cicandeau chanoyne de leglise / davranches et consierge de la maison/ episcopalle dudit avranches et pareillement/de jehan laurens recepveur temporel/de la baronnie davranches Item et sil/ est trouve que ledit caussin rende / deument cesdits comptes il vieult et ordonne / que ledit caussin si cest son plaisir soit/ et entende alexecution de sondit/testament avec ses executeurs et / quil soit alaudicion des comptes de/ses repveurs et fermiers de sainct/philebert Cest assavoir de jehan/de morceing maistre pierre de morceing / et jehan bissot recepveurs de la terre de / freneuze et quil execute sondit testament / avec sesdits executeurs en ensuyvant et / actomplissant le vouloir et desir dudit / testateur ainsy que autre foy et bien souvent/il luy a declaree pour la fondacion / de la soubz chanterie en ladite eglise/davranches

[fol. 9r] Item Et pour ce que ledit seigneur/testateur doit a jehan gilles procureur/de bas vendomays de prest a luy faict/la somme de cinquante livres tournois a/ este expensee es reparacions [de]/abbaye de sainct george du boys / et quil avoit ja pieca ordonne et commande / a messire jehan daguenet quil vendist / les blez de ladite abbaye et des / deniers qui en sortiront quil paiast / ledit gilles deladite somme de L lb et/aussy les aultres crediteurs dudit seigneur pour / raison des mises et reparacions de ladite/abbaye il vieult et ordonne que sy lesdits / blez ne sont venduz quilz soient et que/lesdits crediteurs en soient 
paiez et sy largent / desdits blez ne suffist il a ordonne quil / soient paiez de ce qui restera sur les/deniers de sa depance ordinaire et/ extraordinaire

Item et vieult aussy que maistre jehan/le machon maistre de novices dudit/monastere de sainct george soit/paie de ses gaiges dun an et cinq moys/cest assavoir de six escuz par an et pour/les cinq moys a la raison de ladite somme

[fol. 9v] Desquelles chouses ledit seigneur testateur/nous ademande instrument pour / luy ses executeurs procureurs crediteurs / leigataires et aultres pretendens / interest fait et passe ou cloistre / de ladite eglise monseigneur sainct martin / de tours en la maison canonialle / dudit maistre jehan bouhalle presents/mondit seigneur bouhale et messire mace/le sourd Tesmoings a ce requis / et appellez

\section{Bibliographie}

Anselme, le Père, Histoire généalogique et chronologique de la maison royale de France et des grands officiers de la couronne, Paris, La Compagnie des libraires, t. I, 1726.

Baluze, Étienne, Histoire généalogique de la Maison d’Auvergne, Paris, A. Dezallier, t. II, 1708 .

BAnde, Alexandre, Le cœur du roi. Les Capétiens et les sépultures multiples, Paris, Taillandier, 2009.

Beaurepaire, Charles (de), "Testament de Louis de Bourbon, évêque d'Avranches, 1510 ", Bulletin de la Société de l'Histoire de Normandie, t. VII, 1895, p. 344-355.

Beaurepaire, Charles (de), Notes manuscrites sur le diocèse d'Avranches, Bibl. mun. d'Avranches, ms 287, [sd], p. 3-9 pour les tournées d'ordres, p. 47 pour la réunion avec le chapitre, p. 51 pour la réconciliation par l'évêque de l'abbatiale du Mont Saint-Michel.

Brown, Elizabeth, «Philippe le Bel and the remains of saint Louis», La Gazette des beaux-arts, t. 95, 1980, p. 175-182.

Brown, Elizabeth, «Death and the Human Body in the later Middle Ages. The Legislation of Boniface VIII on the Division of the Corpse», Viator, t. XII, 1981.

Canivez, Joseph-Marie, Statuta Capitulorum Generalium ordinis Cisterciensis, t. VI, Bibliothèque de la Revue d'Histoire ecclésiastique, fasc. XIV, Louvain, [sn], 1938.

CAsset, Marie, "Les évêques d'Avranches dans leurs murs au Moyen Âge, à SaintPhilibert-sur-Risle et au Parc», Revue de l'Avranchin et du Pays de Granville, t. 87, 2010, fasc. 424, p. 371-372.

Charlier, Philippe et Georges, Patrice, «Techniques de préparation du corps et d'embaumement à la fin du Moyen Âge", Inhumations de prestige ou prestige de l'inhumation? Expressions du pouvoir dans l'au-delà (IVe-XVe siècle), Armelle Alduc-Le Bagousse (éd.), Caen, Publications du CRAHM, 2009, p. 405-437.

Chevalier, Bernard, Tours, ville royale: 1356-1520, origine et développement d'une capitale à la fin du Moyen Âge, Paris, Publications de la Sorbonne, 1975.

Chevalier, Bernard, Guillaume Briçonnet (v. 1445-1514), un cardinal-ministre au début de la Renaissance, Rennes, Presses universitaires de Rennes, 2005. 
Chiffoleau, Jacques, La comptabilité de l'au-delà: les hommes, la mort et la religion dans la région d'Avignon à la fin du Moyen Âge, vers 1320-vers 1480, Paris, Albin Michel, 2011.

Courtemanche, Danielle, Euvrer pour la postérité: les testaments parisiens des gens $d u$ roi au début $d u X V^{e}$ siècle, Paris, L'Harmattan, 1997.

Desportes, Pierre, Testaments saint-quentinnois $d u X I V^{e}$ siècle, Paris, CNRS Éditions, 2003.

Dictionnaire d'Histoire et de Géographie ecclésiastiques, Alfred BAudrillart (dir.), t. X, Paris, Letouzey et Ané, 1938.

Folz, Robert, «L'esprit religieux du testament bourguignon au Moyen Âge», Mémoires de la Société pour l'histoire du droit et des institutions des anciens pays bourguignons, comtois et romands, t. 17, 1955, p. 7-28.

Fournié, Michelle, Le ciel peut-il attendre? Le culte du purgatoire dans le Midi de la France (v. 1320-v. 1520), Paris, Le Cerf, 1997.

Funérailles de Georges d'Amboise, archevêque de Rouen, avec une introduction par Édouard Frère, Rouen, imprimerie Henry Boissel, 1864.

Gallia christiana in Provincias Ecclesiasticas distributa..., D. SAmarthanus et al. (éd.), Paris, $1715-1865,16$ vol.

Gaude-Ferragu, Murielle, D’or et de cendres: les funérailles des princes dans le royaume de France au bas Moyen Âge, Villeneuve d'Ascq, Presses universitaires du Septentrion, 2005.

Gaude-Ferragu, Murielle, «Les femmes et la mort: sépultures et funérailles des reines et des princesses au bas Moyen Âge", in Inhumations de prestige ou prestige de l'inhumation? Expressions du pouvoir dans l'au-delà ( $I V^{e}-X V^{e}$ siècle), Armelle Alduc-Le Bagousse (éd.), Caen, Publications du CRAHM, 2009, p. 383-404.

Hayez, Anne-Marie, "Clauses pieuses des testaments avignonnais au XIV siècle", in La piété populaire au Moyen Âge, Actes du $99^{\mathrm{e}}$ congrès des sociétés savantes, Paris, CTHS, 1977, t. I, p. 129-159.

JouRD'HEUIL, Jean-Vincent, «La cathédrale est-elle un lieu de sépulture de prestige pour les évêques? Étude des sièges entre Loire et Meuse du XI ${ }^{\mathrm{e}}$ au XV ${ }^{\mathrm{e}}$ siècle", Inhumations de prestige ou prestige de l'inhumation? Expressions du pouvoir dans l'au-delà ( $I V^{e}-X V^{e}$ siècle), Armelle Alduc-Le Bagousse (éd.), Caen, Publications du CRAHM, 2009, p. 243-264.

JouRD'HEUIL, Jean-Vincent, La mort et la sépulture des évêques des provinces ecclésiastiques de Lyon, Reims, Rouen et Sens du XI au XV siècle, thèse de doctorat, Université de Bourgogne, 2010.

Julerot, Véronique, «Y a un grant desordre» : élections épiscopales et schismes diocésains en France sous Charles VIII, Paris, Publications de la Sorbonne, 2006.

Lecanu, Auguste-François, Histoire du diocèse de Coutances et Avranches depuis les temps les plus reculés jusqu'à nos jour, Coutances, Sallettes, t. I, 1877-1878.

Lechat, Jean-Baptiste, "Répertoire des visites canoniques de l'ancien diocèse d'Avranches», extrait de la Revue de l'Avranchin et du pays de Granville, t. 37, 1957, 12 p.

LEDRU, Émile, "Le prieuré Saint-Thomas d'Epernon, étude historique», extrait des Archives historiques du diocèse de Chartres, Chartres, 1899, p. 293-340. 
LE HÉRICHER, Édouard, Avranchin monumental et historique, Brionne, Gérard Montfort, 1980 .

Lelong, Charles, La basilique Saint-Martin de Tours, Chambray, CLD, 1986.

Longnon, Auguste, Pouillés de la province de Tours, Paris, Klincksieck, 1903.

Lorcin, Marie-Thérèse, Vivre et mourir en Lyonnais à la fin du Moyen Âge, Paris, Éditions du CNRS, 1981.

Marandet, Marie-Claude, Le souci de l'au-delà: la pratique testamentaire dans la région toulousaine, 1300-1450, Perpignan, Presses universitaires de Perpignan, 1998.

Matthieu, 19, 5.

Matz, Jean-Michel et Comte, François, Diocèse d'Angers, collection Fasti ecclesiae gallicanae, t. 7, Turnhout, Brepols, 2003.

Matz, Jean-Michel, "La sainteté épiscopale en France (XV'edébut XVI ${ }^{\mathrm{e}}$ siècle) », in Yves Mahyeuc, 1462-1541, Rennes en Renaissance, Augustin PIC et Georges Provost (dir.), Rennes, Presses universitaires de Rennes, 2010, p. 249-264.

Millet, Hélène et Poulle, Emmanuel, Le vote de la soustraction d'obédience en 1398, t. I, Paris, CNRS Éditions, 1988.

MÉnARd, (Chanoine), "Procès-verbal de la visite des églises de Saint-James par Mgr Louis de Bourbon, évêque d'Avranches. 7 novembre 1485 ", pièce justificative XIV de l'Histoire de la ville de Saint-James de Beuvron, in Mémoires de la Société académique du Cotentin, t. XII, Avranches, Perrin, 1896, p. 105-106.

Nicole, Julien (maître), Histoire chronologique des évêques d'Avranches, (de), Charles A. de Beaurepaire (éd.), extrait des Mélanges de la Société d'Histoire de Normandie, Rouen, Lestringeant, Paris, Picard, 1898.

Noblet, Julien, En perpétuelle mémoire, collégiales castrales et saintes chapelles à vocation funéraire en France, 1450-1560, Rennes, Presses universitaires de Rennes, 2009.

Paravicini-Bagliani, Agostino, Boniface VIII, un pape hérétique?, Paris, Payot, 2003, p. 231-238.

Pasche, Véronique, "Pour le salut de mon âme", les Lausannois face à la mort, $X I V^{e}$ siècle, Lausanne, Université de Lausanne, 1989.

PÉGeOt, Pierre, «La noblesse comtoise face à la mort», Francia, t. 11, 1983, p. 303-318.

PÉlicier, Pierre (éd.), Lettres de Charles VIII, Paris, Société de l'Histoire de France, t. III, 1898-1905.

Pigeon, Émile Auber, Le diocèse d'Avranches, Coutances, Sallettes, 1888.

Stouff, Louis, «Les Provençaux et la mort dans les testaments (XIII ${ }^{\mathrm{e}}$ XIV $^{\mathrm{e}}$ siècles) », in La mort et l'au-delà en France méridionale (XII ${ }^{e}-X V^{e}$ siècles), Cahiers de Fanjeaux, t. 33, Toulouse, 1998, p. 199-222.

Taвbagh, Vincent, Diocèse de Sens, collection Fasti ecclesiae gallicanae, t. 11, Turnhout, Brepols, 2010. 


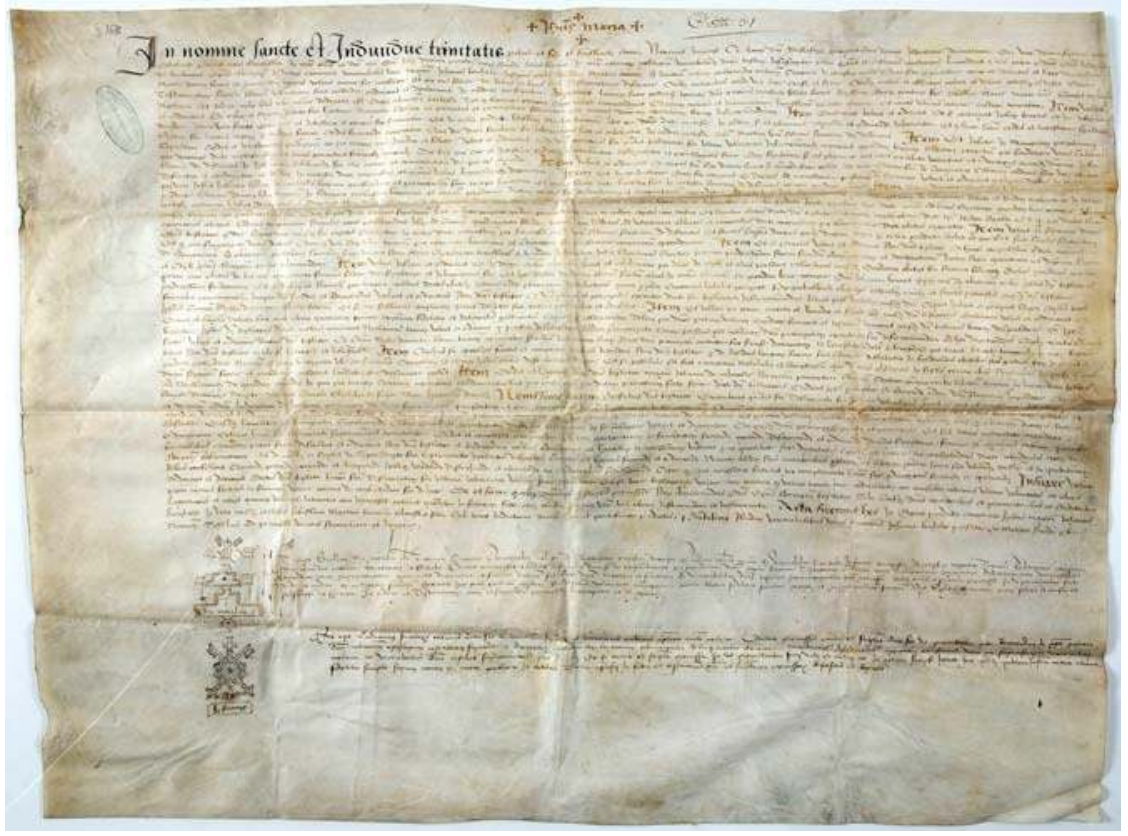

Fig. 1: Le testament de Louis de Bourbon-Vendôme, Rouen, Arch. dép. Seine-Maritime, G 8680 (recto)

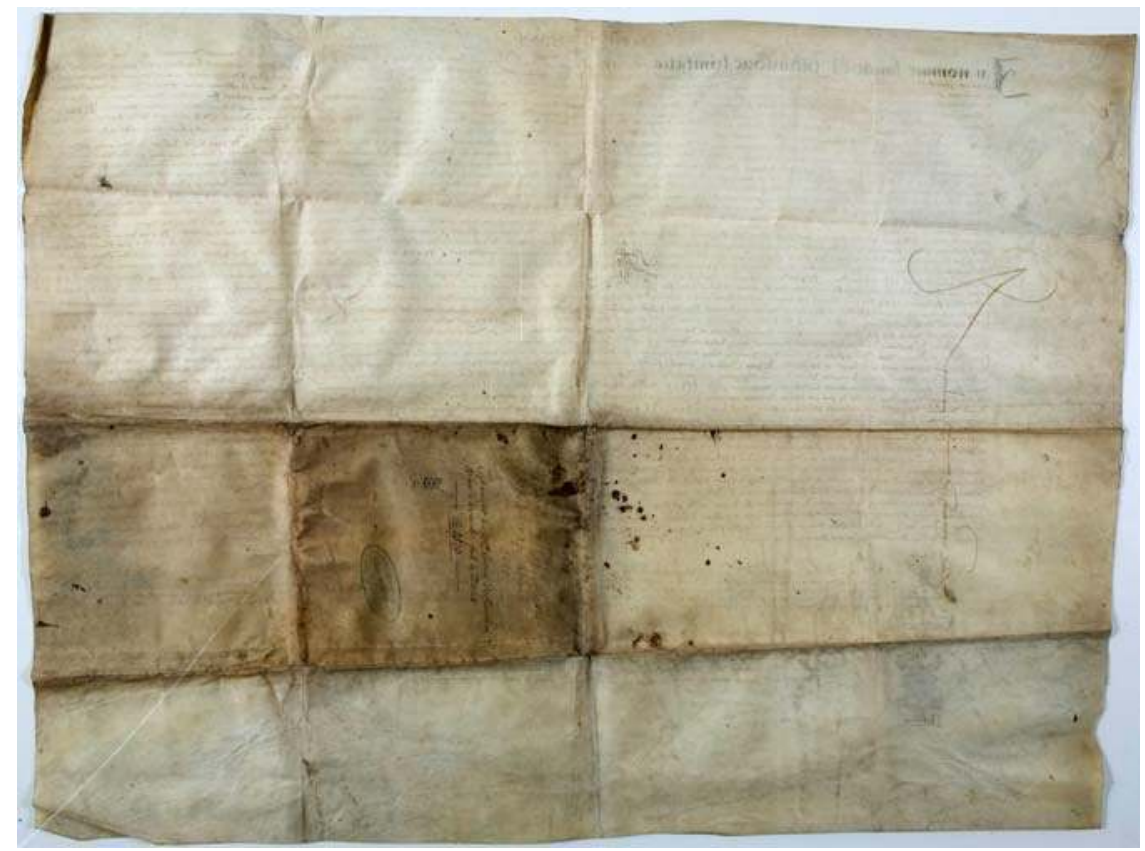

Fig. 2: Le testament de Louis de Bourbon-Vendôme, Rouen, Arch. dép. Seine-Maritime, G 8680 (verso) 